\title{
Religious Education in Schools as a Necessity in a Secular State: the Perspective in Catalonia
}

\author{
Núria Llevot-Calvet, Olga Bernad-Cavero and Jordi Garreta-Bochaca
}

\section{1 \\ Introduction}

The international migrations of the end of the twentieth and beginning of the twenty-first centuries have generated fundamental changes in the social reality of Spain and Catalonia. The latter was one of the first of the Autonomous Communities of Spain to receive, and have to respond to, foreign immigration from a greater diversity of origins from the earliest years of this phenomenon. The inclusion of new cultures and religions into the pre-existing Catalan social fabric and the guarantee of good reception for the new communities by Catalan society have been the two most important axes of the policies of the Catalan autonomous administration (Generalitat de Catalonia) in recent years.

In this context, schools have found themselves faced with the necessity to transform and innovate (Sanuy et al., 2017a), both in their theoretical approaches and in their teaching methodology, with the aim of dealing with this new reality in the schools. In this sense, since the mid-199os, pre-schools (people aged $3^{-6}$ ) and primary schools (6-12) have become a fundamental tool to manage cultural and religious diversity in Catalonia from a local setting within the working framework established by the Generalitat de Catalunya (Garreta, 2006; Llevot et al., 2016 and 2017). This has meant relative experience in drawing up discourses and designing policies regarding cultural and religious diversity within the Spanish framework.

Education has become one of the capital elements of modern society. The process of training deals with educating people in becoming part of a complex and changing society; the latter needs to be prepared to assimilate the novelties of cultural, social and technical evolution. Education is also a tool that can be very useful for generating understanding, respect and coexistence and for favoring social cohesion among people and groups with different cultural and religious traditions. It must be borne in mind that, throughout its history, Catalan society has been enriched by the reception of various migratory flows. However, in recent decades, the nature of this influx of immigrants has 
changed. The fact that they come from varied origins implies the incorporation of a cultural, linguistic and religious diversity that was unthinkable a few years ago (Garreta, 2011; Garreta, Llevot, 2011; Llevot et al, 2017). Thus, the education system has had to respond, with a positive outlook, to the increase in diversity and its political and social recognition (Garreta, 2003; Bernad, 2016; Giró, Andrés, 2018).

In Spain, educational decentralization has led to policies in this field developing in diverse ways. However, the results are not very different, given that these are always in the framework of the idea of interculturality and under the general directives of the ministerial educational administration (see CIDE, 2005; Fernández, García, 2015; Santos, 2017). J. Garreta (2003 and 2006) showed that, at the start of the new century, the dynamics of implantation of intercultural education (a dominant focus in that moment principally through the influence of the European Union) was slow. Consequently, it was not easy to put the discourse into practice as there was no general proposal or specific focus on how to do it (the teaching staff were not given adequate orientation or resources, nor were they obliged to define themselves and act accordingly). Despite this, one can state that important steps had been taken (even though more should have been done) to incorporate the students and families of foreign origin or gypsies into the education system. The few studies that have compared different Autonomous Communities (especially the work of the CIDE (2005)) have shown the following. Work has been done to incorporate students at different moments of their school path and the academic year; the teaching of the school's vehicular language (in some cases, support has also been given to the learning of the languages of origin) has been taken into consideration; plans have been drawn up for the reception of families and students; the training of the teaching staff has been enhanced; initiatives for translation and/or intercultural mediation have been set up; specific materials have been prepared and included in the curriculum; etc. It is also true that it was not until very recently that the aspect of religious diversity started being given consideration when dealing with cultural diversity. It seems to us that, after being scarcely considered, the discourse and the actions regarding cultural diversity have been consolidating; relevant issues are now emerging, such as the afore-mentioned mediators and translators, the specific materials, the adaptation of the curriculum to cultural diversity, etc. However, despite this development, the research still indicates that it is necessary to better articulate the necessities through actions and the discourse through practice, as well as to provide a more advanced training for everyone involved in the schools (see, among others: Llevot, 2006; Aguado, 2011; Márquez-Lepe, García-Cano, 2014; Escarbajal, Leiva, 2017). Moreover, it is common to believe it is necessary to 
continue to study in order to better know, in a comparative and methodologically plural way, what has been done, what evaluation this has received by the different agents involved and how this could be improved. As shown above, Spain has taken steps in the valuation of cultural diversity in the classroom and has evolved, in just a few years, from a centralized educational system (where cultural diversity, focused on gypsies, was undervalued) to a decentralized autonomous system, much closer to an intercultural pedagogical model (Essomba, 2014) and in which the cultural pluralism of the State has been accentuated. This intercultural education has gradually incorporated a more general approach to seeking social cohesion and inclusion.

Thus, the growing cultural and religious diversity in Catalan society has highlighted the limitations of a social and educational model. These have become more notable with this demographic evolution (Griera, 2016). In fact, this debate has been ongoing since the start of the democratic transition and has placed the school at the center of attention, as a microcosm of what the society produces (Sanuy et al., 2017b). In this line, one of the challenges the school faces is how to respond to not only the cultural diversity but also to the religious diversity in our society and in schools - a debate from which the teacher-training faculties are not excluded (Bernad, Llevot, 2018a).

Focusing on the religious question, the Spanish Constitution recognizes the right of families to choose the religious and moral training for their children in accordance with their own beliefs. This right has been upheld by the successive education laws that have been implemented since the advent of democracy. Thus, in the Spanish educational system, the subject of religion is mandatory for the school and optative for the students. When the latter opt to study religion, they can choose between those religions that have signed cooperation agreements with the State (Catholic, Evangelical, Muslim and Jewish). However, various studies (Tarrés, Roson, 2009; Viñao, 2014; Llevot et al., 2017) show the hegemonic role of the Catholic religion and the scant implantation of the other three.

In this general setting, we present what happens in the pre-schools and the primary schools of the Catalan territory; specifically, how religious diversity is dealt with, and which actions are being carried out in the schools. To this end, we use two approaches. ${ }^{1}$ First, we present the results of a survey of representatives of the management teams from 380 public schools in Catalonia. This is

1 The data used are from the Proyecto Recercaixa 2015 and the subvention of the RELIG programme of the Generalitat de Catalunya for university research projects in the field of religious diversity. To extend this, one can consult Garreta et al., 2018. 
complemented with in-depth interviews (qualitative methodology) of a sample from 16 schools who stand out in the survey for their actions and management regarding the treatment of cultural and/or religious diversity. ${ }^{2}$

The survey is useful for a first approach to the schools, and it shows that the average number of pupils of foreign origin is $19.76 \%$, the largest proportion of whom are of Maghrebi origin. A characteristic of the education system is that despite having a general framework -established by the legislation- within which educational action is developed, each school adapts the elements it has available to its circumstances. Regarding the arrival of pupils with characteristics initially not envisaged by the legal framework, the schools have had to adapt their resources and seek other new ones to tackle these necessities. Teachers have been impelled to prepare new strategies to involve the students and their families, and have prioritized transversal work and, in short, have had to improvise and experiment faced in an unexpected situation.

The survey shows that the cultural diversity in society is analyzed with the pupils in many centers. Specifically, only $15.5 \%$ do nothing about this. As could be expected, the response that said they acted was more frequent in schools that have a higher presence of foreign-origin students. The most common actions are working on cultural diversity in the curriculum (60.3\%) and organizing intercultural days (32.6\%). Other less frequent actions are (in this order) the adaptation of menus, projects and activities in the classroom, specific actions of communication and training of family members, and work on religious diversity.

In more detail, we can see that, among those surveyed, the ones responding that they take cultural diversity into consideration in the curriculum indicate that this is mainly introduced in the subjects of social and natural environment $(42.9 \%)$, also in tutoring $(12.2 \%)$, ethics/values $(25.3 \%)$ and religion $(22 \%)$. It is true that $36.3 \%$ of the schools receive external support to act on cultural diversity (from the Generalitat de Catalunya, especially from the Department of Education's teams of Language and Social Cohesion (ELIC), see: http://xtec.gencat.cat/ca/serveis/sez/elic/), a percentage that increases in line with the rise in the proportion of foreign-origin students in the school.

2 Taking the concept of good practices proposed by Ritacco (2011) as a reference, these good practices could be understood as convex and convergent actions within the same framework of action (Sanuy et al., 2017b). 
TABLE 25.1 Actions/activities carried out while working on cultural diversity

Actions mentioned spontaneously

Percentage

Working on the curriculum

60.3

Intercultural days

32.6

Training of teachers

Training for the families

14.2

Specific communication activities

16.1

Adaptation of menus

27.1

Reception

6.6

Reception class

Support

Curricular adaptation

Human rights' days

Projects specific center

Working on religious diversity

Tutoring

Classes language of origin

Intercultural mediation

Organization groups

Specific to classroom

Activities for foreign families

Others

None

SOURCE: PROYECTO RECERCAIXA 2015; GARRETA ET AL., 2018.

On focusing interest on the presence/absence of cultural and religious diversity in the documents from the schools, we can observe that cultural diversity receives more attention than religious diversity (and is taken more into consideration as the number of foreign origin pupils increases) in the Centre Curricular Projects $(\mathrm{PCC})^{3}$ and Centre Educational Projects (PEC).${ }^{4}$ A minority does

3 The PEC is made up of the pedagogical and organisational principles that should run all the educational actions, while the PCC is an eminently pedagogical document that constitutes a basic instrument for defining the approaches developed in the educational project respecting the prescriptions of the official curriculum.

4 Document that defines how the school works: guiding principles that differentiate it from other centres, actions for adaptation to the surroundings; lines of attention to diversity and 
not contemplate cultural diversity in its plans - the Plan for coexistence being where these themes are most frequently reflected. In contrast, when we refer to religious diversity, the reality is different. Moreover, in the majority of schools, no one is responsible for managing religious diversity. Although $28.4 \%$ claim there is someone in charge of this, they are often referring to the teacher of Catholic religion and, to a lesser degree, to the management team or the commission for coexistence.

Regarding the teaching of religion, in primary schools, "the areas of religion and education in social and civic values are mandatory for the schools and optative for the families" (Departament d'Ensenyament, 2015). In other words, when enrolling their children, families can choose whether their offspring study the subject of religion or an alternative. Currently, in line with the Organic Law for the Improvement of Educational Quality (LOMCE in its Spanish initials, 2013), ${ }^{5}$ the latter option means social and civic values. Previously, the alternative subject had a wider spectrum according to the criteria of the school (another change introduced by the LOMCE is that both subjects are evaluable and have the same teaching hours). Regarding the area of religion, the Law stipulates there is a choice between the Catholic, Evangelical, Jewish and Muslim religions. However, in practice, as the results of the survey show, in public schools, possibly conditioned by the demand of the families, alternative educational attention and Catholic religion are taught mostly, the presence of the Evangelical religion being almost imperceptible and the other two religions, null. However, in some centers, on their own initiative, the Catholic religion teachers introduce a view of other religions into their subject as religious culture (see Garreta et al., 2019). On the other hand, and for various reasons, either due to the ideas of the center or the choice of the families, we also find centers that only teach the subject of religion and others that only teach the alternative subject.

However, the answers from those surveyed mainly indicate that religions should be taught outside the school $(75 \%) .85 .5 \%$ of the people interviewed consider that it is important to work with the religious diversity of pupils that exists in society (approximately half of the schools indicate that they have opted for a transversal approach, focusing on objects other than religion/values, such as social environment, music or tutoring). However, only a minority

the mid-term objectives; breakdown of the main lines of organisation that are defined in the curricular project, etc.

5 For more details about this law, consult http://www.educacionyfp.gob.es/educacion/mc/ lomce/lomce.html. 
of centers (1.8\%) have received external support to work on it, and this is mainly in those that have a higher presence of foreign-origin pupils.

The representatives of the management teams surveyed indicate that cultural and religious diversity has become "normalized" nowadays. Does this mean, perhaps, that it has ceased to be a "problem" in their schools? Do they now have enough experience and training to know how to deal with it and respond adequately to the needs of their students? Do they work on and respect the differences? According to our study, professionals' knowledge about pupils of foreign origin, their countries and their cultures of origin, the different religions (one of the training requirements in the early years of this immigration (see Garreta, 2003 and 2006)) is no longer a priority in the training plans. However, coexistence in the centers, among pupils from different cultural and ethnic groups and their scholarly and social integration, continues to be an evident necessity. Some of the new demands for training are education in values, management of emotions, organization of the classroom, and, especially, practical resources (like a "recipe book"). In general, they think they have already received sufficient theoretical training, and what is needed now are strategies and practical activities to be able to implant in the classroom immediately. In fact, $21.8 \%$ of those surveyed believe they need strategies for conflict resolution to improve their response to cultural diversity.

Thus, the training of teachers to work on cultural and religious diversity is considered sufficient, but less so when referring to religious diversity $(77.9 \%$ consider their training adequate for cultural diversity and $50 \%$ for religious diversity). In some cases, they allege that, since they do not have diversity in the school, they do not consider this necessary. This option is in line with what has already been pointed out: the opinion, shared by many professionals, that it is the level of cultural diversity in the classroom (presence of foreign-origin students or gypsies) that justifies initiatives in this field. In other words, the greater the presence of foreign-origin pupils (or gypsies), the more the actions that are put into movement and the more it is frequent to believe that it is not necessary to take them in schools without diversity, where the idea that society is diverse culturally is taken less into consideration, and where this question has to be dealt with for all the pupils.

As indicated above, Catalan schools nowadays have much experience in the reception of pupils from other cultures and in the treatment of cultural diversity, but do not have the same degree of experience as far as religious diversity 
is concerned. Probably because of that, this subject is not considered as a priority in the training plans or among the necessities expressed by the management teams. Factors like the training received, the teaching experience, the school culture, the organization, the context, the resources and the materials they have, play an important role in the school's micro-politics, and they are reflected in the way this topic is approached in the projects and actions.

The influence of socio-economic and educational factors is highlighted, especially in the schools in depressed neighborhoods. These factors imply great social differentials in a group labelled uniformly as of "immigrant origin". In this sense, differentiated responses are designed to contemplate the multiple realities. Thinking that their function must go beyond the purely instructive aspects, and faced with the evidence of some families' serious socio-economic difficulties, teachers are impelled to seek solutions to palliate the necessities manifested by the children - needs that greatly hinder normal schooling. Given the fall in financial and human resources from the educational administration (especially due to the economic crisis), the schools request financial support from some foundations and also undertake synergies by working with entities in their surroundings. As a differential trait, some privately owned schools with grant-aid agreements with the public administration (known as "concertadas" in Spain) receive help and resources from their own foundations and from other schools. Therefore, besides requesting resources such as grants, they implement actions such as opening the school library after school hours to facilitate the children in doing their homework, or organize summer camps and activities. Generally, they do so with the support of volunteers or associations, including Save the Children.

The models of management relating to diversity does not follow uniformed models valid for all cases, as each school has to build its own model, adapted to its specific situation. Diversity is considered a "normal" trait in the school, where equality is built from the recognition of differences. Some schools that have transformed their way of being, doing and relating to others, seek a defining trait that brings together and gives sense to the different activities, curricular or not, that are carried out, and choose to create a great school project shared with the community as a "stamp" of identity. In contrast, other centers opt to weave a network of small actions and of small projects that give sense to what they do from day to day, thus creating a school culture.

Other schools with a trajectory of community work seek the involvement of the community by networking with the neighborhood entities. They undertake participative processes to convert the school into a space for learning, participation and communication, where everyone learns and at the same time teaches the other and feels to be listened to. However, the grant-aided schools 
that have been visited (which belong to a religious order with a number of schools scattered around Catalonia) have a shared project ideal for all the centers, which dictates (and unifies) the guidelines that must be followed and includes the peculiarities of each center. All these schools define themselves as inclusive, but some work more on the aim of extending the equality of opportunities to all the families that make up the community. They work basing on the understanding that we are different and that this difference makes the reality as rich and complex as it is.

To encourage mutual respect, cooperation and knowledge of the other cultures present in the school, as well as to choose the most adequate teaching activities, it is common for them to work in cooperation with each other (with the help of volunteers or family members and having established the same objectives) on other aspects that characterize the everyday life of the school. For example, the cleaning of the dining room, the attention for the school vegetable garden, and other extra-scholar reinforcement activities.

Generally, families do not get involved with the education of their children, as indicated by the interviewees from the schools that carry out the cited good practices regarding the cultural and religious diversity. On the other hand, various studies indicate the involvement of parents (which mainly covers these three aspects: school-family communication, participation of the families in the school and participation of the families at home) as one of the determining factors for success at school (Bernad, 2016). Given the pressing need to improve this aspect, all the centers visited have implemented actions to improve schoolfamily communication, incentivize the participation of families in the school's activities and facilitate the follow-up of their children's progress in the school. Among others, the families are invited to enter the classrooms to see what the children do and to attend workshops designed to show how the school works and what the methodologies used are. They are also encouraged to participate in such teaching-learning activities as class projects or interactive groups. Lastly, some schools offer the families the possibility of participating in running the center through mixed commissions, besides making the mothers and fathers class delegates, creating a family council, scheduling meetings with teachers, etc. These actions relate to the working dynamics of the centers and the attitudes of the professionals who work in them.

The mentioned interviews enable us to analyze what teachers think about the issue of cultural and religious diversity, and what is their position regarding the official curriculum. When the focus is on education policies regarding these themes, reference is quickly made to what they believe to be conditioning their work, namely the series of education laws in Spain, parallel to the changes in the ruling parties, as the application of each of these laws implies curricular changes in different subjects. Secondly, the interviewees focus on 
religious diversity in schools, which they currently place in a multi-cultural and globalized context in which cultural and religious diversity is managed depending on a wide range of factors, as shown below.

Although the law states that teaching the subject of Religion is mandatory for the centers and optional for the pupils, in public schools we can detect a wide spectrum (possibly conditioned by the choice of the families) of school provisions that range from schools that only teach Catholicism to schools that only offer an alternative subject, while some others offer both options. The majority of the public schools that have been visited, given their successful experiences, often do not work on the religious component besides the subject of Religion. In contrast, the question of values and ethics is dealt with transversally or through various specific actions such as the $3^{-12}$ philosophy program or in tutorials. If the subject of religion is not taught, religious culture is dealt with transversally in other subjects like social environment and tutoring.

One must be more specific, given that when looking at Catholicism (which, we recall, is the most habitual of the optional religions in the survey presented above) and although the curriculum for religion is established at the state level by the Spanish Episcopal Conference, most have adapted the program to the current situation by including knowledge of other religions, emphasizing values and relegating religious practices to the family sphere. At this point, it is notable that, despite their Catholic confessional ideology, the grant-aided centers visited tend to offer a mandatory subject called Religious Cultures to all pupils. It has its own specific content, it includes the study of the other majority religions and the study of the values shared by the different confessions (based on universal human rights).

Independently of whether they choose to attend the Religion class or the alternative, a good part of the foreign-origin pupils tends to go to places of worship after school hours or at the weekend. There, as well as following the religious practices, they can attend classes of religion and culture. Even if the legislation contemplates that it is possible to teach four religions in educational centers, in practice only Catholicism is taught (or religious culture in another case) and, in a few centers, the Evangelical religion. One of the reasons adduced for this is the lack of teachers who fulfil the requisites regarding training (especially the need to have a teaching qualification).

The response to cultural and religious diversity in schools in Catalonia shows a diversity of answers and approaches - $\mathrm{a}$ fact that reaffirms that we are witnessing a process of defining and situating these subjects, which have to adapt to 
the changing laws and to the context and actors who intervene, as Garreta (2006 and 2011) and Rey (2012) indicated previously. The analysis of these data shows a set of paradoxical aspects, which are detailed below:

- The legal framework of the education system provokes certain tensions. In a way, the preferential treatment of Catholicism in a non-denominational State is contrary to the teaching of religious diversity and intercultural dialogue. Besides the policies that can evolve with the changes in educational legislation, this preferential treatment converts the subject of religion into an "anomaly" within the school curriculum, and even more so bearing in mind the cultural and religious diversity that has entered into our school environment (Llevot et al., 2016 and 2017). Nevertheless, the efforts made by Religion teachers, in consonance with the school management teams, in order to incorporate cultural and religious diversity into their subject, sometimes even contravening the guidelines of the bishopric, must be recognized.

- Religious diversity is covered by the legislation of the educational administration. However, in reality, this is never really complied with (Llevot et al., 2017). This is partly due to the lack of specialist teachers that meet the established training requisites to teach other religions (Tarrés, Rosón, 2009). We can also observe that the concept of religious diversity is assimilated to the fact of differentiating the subject according to the different recognized religious confessions (Griera, 2016). This favors religious freedom but, at the same time, hinders interculturality and the interreligious dialogue.

- It must also be added that, as a consequence of this legislation that frames the application of religions in schools, it is often the teachers of Catholic religion who attempt to incorporate knowledge of other religions and shared universal values into their subject (of course, from a clearly Christian viewpoint). This initiative, which should be valued as positive and innovative for the religion that is taught this way, inevitably produces a filter that limits the visibility of other possibilities when religious diversity is reduced to this (Llevot et al., 2017). In summary, we cannot have religious diversity if we only teach the subject of Catholic religion.

Public school faces a great challenge regarding cultural diversity, and that is why this diversity is approached as a joint task and projects are undertaken from the schools and the parents' associations (Garreta, 2003; Garreta, Llevot, 2011; Bernad, Llevot, 2016 and 2018a; Sanuy et al., 2017b). Here, we highlight the extraordinary efforts made by the teaching staff to incorporate these aspects into their everyday routines. The study by Garreta (2003) highlighted the organization of intercultural days above all else. However, this activity has now fallen by almost half in this present study. In fact, there is now a high response 
(60.3\%) about working on the curriculum, which indicates that the legacy of performing specific actions (special meetings) without modifying anything else is being overcome. Teachers have had to prepare new strategies to involve the pupils and families, transversal work has been prioritized and in short, they have had to improvise and experiment when faced with an unexpected situation. From this initial process, which starts from a positive professional attitude, new experiences applicable to the working of the schools are accumulated, and these undergo a process of constant revision (Garreta, 2011; Llevot et al., 2017; Giró, Andrés, 2018).

It must not be forgotten that education in cultural and religious diversity does not depend only on the centers, on the families or on the teaching staff. It is unthinkable that themes involving the differences and the coexistence of cultures and religions can be dealt with in the schools idyllically, without any problem, when these are in a context of an increasingly conflictive growing world, in the midst of administrative cutbacks, with a greater or lesser understanding between governments (State and autonomous region) and the different options of public and grant-aided schools, and in situations of injustice and poverty. In this scenario, education in diversity is currently one of the greatest educational challenges, for which the responsibility must necessarily fall on the different social agents. If the problems are generated in relation to movements and conflicts, both local and global, it is unlikely that the solution to these will depend on the values and dynamics of an isolated school or community, although some values and some policies can help more than others to facilitate a good coexistence (see actual experiences in Bernad, Llevot, 2018b). However, given that coexistence is not a synonym for harmony or easiness, rethinking the meaning of this term will help us understand some attitudes that express the willingness to avoid involvement in this debate.

All these are aspects that must be re-thought in the training of future teachers (Bernad, Llevot, 2018a). It is not possible to envisage diversity in schools without taking into consideration the globalized society in which they are rooted, nor the tensions that the subject of differences can originate. One of the most tenacious uncertainties of our times, the one studied by De Sousa (2016), is the difficulty of combining the right to equality and the right to difference.

Returning to the concept of good practices proposed by Ritacco (2011), this is precisely in the common framework of action that our study emphasizes. It is also the will to integrate the existing diversity into the projects, bearing in mind aspects such as cohesion and interculturality, as well as the functionality of the learning. A school "for everyone", that is democratic, open to the community, and which works in a network where teachers, families and pupils feel 
recognized as participants, are other defining aspects. Some factors to take into account are the leadership of the management team, the intercultural climate, the role of religion, the channels of communication and participation, the attitudes of teachers and families and networking, among others. The type of response to religious diversity that has been carried out in schools shows a diversity of reactions and approaches, which reaffirms that we are in the process of defining and locating this subject, one that must adapt to changing laws and the context and actors who intervene (Llevot et al., 2017).

A certain contrast is observed between the experience of religiosity among many recently arrived groups and the increasingly agnostic manifestation of the indigenous population. We believe that the gap that opens in this sense hinders intercultural relations and dialogue and, at the same time, the dynamics inside the educational community and society as a whole. However, some cases have managed to turn the school into a space for understanding and mutual recognition.

A basic premise is actively listening to the necessities and demands, together with sharing one's own, and a shared design and application of the initiatives. The atmosphere in the center cannot be unlinked from mutual trust and the feeling of belonging to the community. To create a real link, it is necessary to make it very strong, solid and, for that reason, the center cannot ignore the social and economic needs of the families, nor even the problems of dislocation and rootlessness. In truth, the school cannot solve many of the social problems that affect them, but they can listen to them and accompany them, and a way to do so is to understand the importance that learning the religion of origin has for some communities. To this end, beyond the single mind-set, it is essential that the school allows the differences to arise and be expressed. It must be given space and time to learn how to think about them, and especially to converse in a space inside the school, which allows to be open to philosophical questions, to religious themes, etc.

Lastly, we have to mention Carlos Skliar (2010), who invites us to consider education as the place that opens a possibility and responsibility towards the existence of the other, of all humankind. Education consists of meeting the specific other, face to face. This meeting is with a specific and singular face, name, word, language, situation, emotion and knowledge. This must be the way to be open to what is different and to learn from each other. 